\title{
Platzsparende und robuste Wärmetauscher
}

\author{
Beschichtete Plattenwärmetauscher zum Heizen und Kühlen wollen zukünftig in der Galvano- und \\ Oberflächentechnik Maßstäbe setzen, indem sie eine hohe chemische Beständigkeit mitbringen \\ und gleichzeitig einen geringen Platzbedarf aufweisen.
}

Entsteht bei einem Prozess ein Wärmeeintrag, zum Beispiel durch die Umgebungswärme, Gleichrichter oder eine exotherme Reaktion, so lässt sich dieser mit Hilfe von Wärmetauschern kompensieren. Dabei zirkuliert die Prozessflüssigkeit im Behälter um den Wärmetauscher und erreicht so die gewünschte Arbeitstemperatur. Wärmeverluste während des Produktionsprozesses lassen sich so ausgleichen.

\section{Hohe chemische Beständigkeit und hervorragende Antihafteigenschaften}

Die beschichteten Plattenwärmetauscher mit dem Namen Synotherm bestehen aus

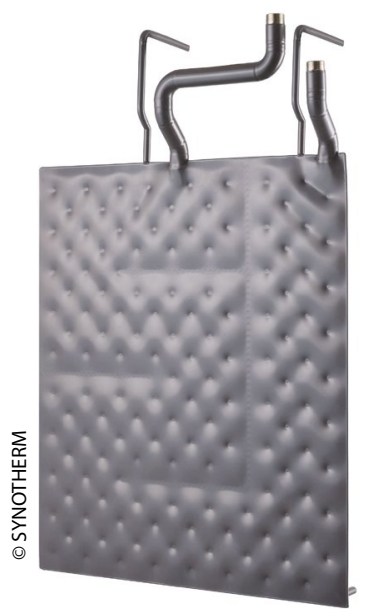

Der Wärmetauscher ist mit Fluorpolymer beschichtet.

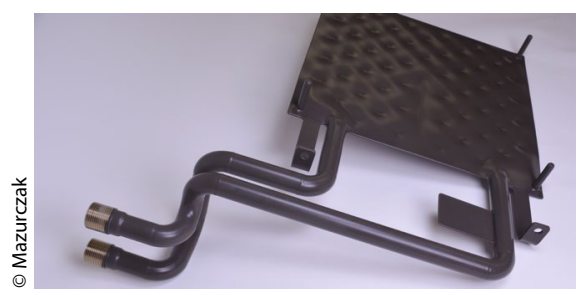

Eine abgewinkelte Verrohrung soll die Montage im Behälter erleichtern. einem metallischen Grundkörper, der dank seiner kompakten, leichten und druckfesten Bauweise eine hohe Lebensdauer und Betriebssicherheit garantieren soll. In einem mehrstufigen Beschichtungsprozess wurde eine Fluorpolymerbeschichtung auf die metallische Oberfläche aufgebracht. Dabei wird die Porenfreiheit der Beschichtung mit einer $100 \%$-Prüfung kontrolliert. Fluorpolymere weisen wesentlich bessere Wärmeübertragungseigenschaften als andere Beschichtungswerkstoffe auf, zudem wird die Inkrustationsneigung bei stark inkrustierenden Medien wie Zink-Phosphatierungen erheblich gesenkt. So sorgt die Beschichtung für eine homogene Wärme-



Die Bautiefe der Anlage beträgt $61 \mathrm{~mm}$ - davon entfallen $11 \mathrm{~mm}$ auf den Wärmetauscherkörper und $50 \mathrm{~mm}$ auf die Abstandshalter zur Behälterwand. übertragung und konstante Prozessbedingungen.

Aufgrund der Beschichtung weisen die Wärmetauscher zudem eine sehr hohe chemische Beständigkeit und gute Antihafteigenschaften auf, und erfüllen so zwei entscheidende Anforderungen für den Einsatz im chemischen Apparatebau. Sie eigenen sich zum Beispiel zum Temperieren von stark sauren Prozessflüssigkeiten.

\section{Geringer Wartungsaufwand sichert hohe Verfügbarkeit}

Die einfache Reinigung und die Verlängerung der Wartungsintervalle soll den Wartungsaufwand verringern und eine hohe Verfügbarkeit der Anlage sicherstellen. Herabfallende Teile oder Sedimente können sich nicht auf dem Wärmetauscherkörper ablagern oder sich in diesem verfangen. Zudem verfügen die beschichteten Plattenwärmetauscher über eine hohe Flächendichte. Das bedeutet, dass hierdurch eine große Wärmetauscherfläche in Verhältnis zum benötigten Bauvolumen zur Verfügung gestellt werden kann. Die Bautiefe der Anlage beträgt nur $61 \mathrm{~mm}-11 \mathrm{~mm}$ Wärmetauscherkörper $+50 \mathrm{~mm}$ Abstandshalter zur Behälterwand. Die Platzersparnis reduziert die Baugrößen und Kosten der Behälter, zudem steht für andere Komponenten mehr Platz zur Verfügung. //

\section{Kontakt}

\section{Matthias Deuner}

Produktmanager Wärmetauscher

Mazurczak GmbH, Schwabach

matthias.deuner@mazurczak.de

www.mazurczak.de

www.synotherm.de 